\title{
Migration Analysis of Credit Risk in Tunisian Banking Sector
}

\author{
Amel Ben Youssef ${ }^{1}$ \\ ${ }^{1}$ Faculty of Economic sciencesand Management of Tunisia, FSEGT, El Manar, Tunis, Tunisia \\ Correspondence: Amel Ben Youssef, Faculty of Economic Sciences and Management of Tunisia, FSEGT, \\ B.P.248 El Manar II 2092 Tunis, Tunisia. Tel: 216-98-544-603. E-mail: amoulaby@ yahoo.fr
}

Received: January 20, 2018

Accepted: January 20, 2018

Online Published: March 9, 2018

\begin{abstract}
In this paper, credit migration matrices are built to measuretransition probabilitiesat Tunisian credit institutions, allowing a comparison of credit risk quality shiftsfor public banks, private banks and leasing companies. We proposeto apply estimating Markov transition matrices using proportions data in order to be adapted to the scarcity of individual dataonloan quality transitions. We employ annual classification of assets issued in theregistration documents and annual financial reports during 2003-2014 period.It's found from the analysis that the risk grade 2 has the greater tendancy to be downgraded than to be upgraded in public banks and in leasing companies.For the other risk grade 3, the upgradation in the category is higher than the downgradation in all cases. The resultsindicate that the public banks are the riskiest credit institution in Tunisia and there is a lack of rigor in loan classification inpublic and private banks. The findings are useful and critical for supervisory purposes and foroptimizing bank credit risk management.
\end{abstract}

\section{Keywords: Transition Matrices, Credit Risk,Banking Sector}

\section{Introduction}

In light of the uncertainty surrounding the credit quality in Tunisian banking sector (IMF, 2012), supervision authorities in this country set awork plan on implementing and strengthening of the bank supervision in Tunisia to become risk-based in compliance with international best practices (Basel II and III) (BCT, 2014).

According toBasel II and III guidelines (BCBS, 2004 and BCBS, 2010), banks are appealed to estimate on themselves their probability of defaultthrough IRB approach, as long as this system is in compliance with minimum quality exigeancesto have validation and approval of supervisors to apply this approach.

Statistical theory presents different methods for conceiving and estimating internal rating models.

For example, the transition or migration matrix represents an aspect of theses systems; Credit migration or transition matrices characterize past changes in credit quality of obligors (Jafry and Schuermann, 2004)

The probability of default could be deducted after establishing a transition matrix which is precisely a probability table (Nicula, 2013) reflecting the transitions between different profiles of debt arrears observed in a credit portfolio between two consecutive periods.

the added value of the transition matrix is to clearly identify the likelihood of damage and descent to the radiation, once we know that the debt is already affected by arrears.

the transition matrix is useful as a basic observation to justify provisioning in accordance with International Accounting Standard 39 (IAS 39), that requires that we reduce the balance sheet value of a debt to the expected net present value of likely residual flows as long as there areobjective signs of an emerging risk.

transitions can also be used to plan and prioritize the management of arrears and recovery activities. by identifying the most severe deterioration of points, the institution has interest to focus on these critical phases in 
the evolution of borrowers' behavior to avoid an ultimate radiation.

Moreover, Basel accord suggested that probability of default shouldn't be measured in isolation of the economy dynamism, but should be in accordance with its change through time and the variability of economic state. Then, estimating the transition matrix between different credit classes in a bank could improve the accuracy of probability of default.

In this paper, we try to assess credit risk at a period from 2003 to 2014 on the basis of transition matrice.

Our model for estimating transition matrices probabilities is based on proportions data in the sense of Jones (2005)

We apply the methodology to individual banks havingsufficient data, and also on leasing companies with appropriate time series data. Then, we compare the behavior of credit quality between public banks, private banks and leasing companies. The samples chosen suit the purposes of this study since they represent a wide range of loans in the banking sector and since the credit risk classication rules are uniform between them.

The motivation for comparing these three credit institutions lies in their different performance. The key research question explored is whether there are differences in the nature of credit risk quality shifts for transition matrices between three credit institutions,public and private banks and leasing companies, through estimatingMarkov transition matrices using proportions data.We find that public banks are the riskiest financial institutions studied while the leasing companies are the least risky. We also find that the estimated transition matrices for public and private banks have an asymmetric and non-monotonic profile, and have little concentration on the diagonals, which shows a lack of rigor in loan classification in these two credit institutions.

The remainder of our paper proceeds as follows. In the next section (2), we review the relevant literature. Section 3 debate the adopted methodology in order to estimate transition matrices. Section 4 presents the dataset used in the study. Section 5 discuss the results obtained. Finally, section 6 concludes the paper

\section{Literature Study}

Migration analysis is one of fundamental techniques of the CreditMetrics methodology. In 1987, J.P.Morgan developed transition matrices to study changes in the credit quality through time (J.P. Morgan \& Co, 1997).

Further, analysingand reporting default rates and grade migrationhistories of borrowers is required by Basel II (BCBS, 2003).

Nicula (2013) outlines the relevance of building migration/transition matrix in credit risk modeling to assess factors affecting moving of a loan belonging to a credit risk grade to another grade.

Lando and Skodeberg (2002) show the importance of estimating transition data based on the full story of rating transitions.

Ivičić and Cerovac (2009)estimate credit transition matrice of non-financial businesses entities. They find rating stability in the migration matrices estimated, especially for the lowest rated companies, but not for the companies belonging to mid-section of the rating structure because they are more exposed to a risk profile change with a higher probability of upgrading than downgrading. It appears also from the results that Probability of defaults are not sensitive to economic activity and that probabilities of transition between different risks categories depend on the economic growth.

Bajaj (2010) proposes tostudy the credit quality through the migration and default rate conditioned on the ratings of debt issuers and on macroeconomic factors. The results provide that the sabilityretention rate in a rating gradeand the level of default rate depend on the debt issuer quality, also that default probilityand the rating migration are cyclical in nature.

Jones (2005)emphasizesthe use of proportions data methodology to estimate transition matrices for the cases where individual Transitions are not available, just informations about aggregate observation on risk category 
state. He demonstrates significance of differences in the transition matrices between different states of the economic cycle.

Grzybowska et al.(2012) compare influence of various migration matrices models on risk estimation. they advise to adopt statistical longitudinal models (GLMM) because they consider economic factors and thus are more appropriate for changing periods as crisis.

\section{The Model}

In order to introduce definition of credit migration matrices and their estimation, let consider $\mathrm{S}$ the transition space; $\mathrm{S}=s_{i}, \ldots, s_{k}$ represent credit classes as provided for in circulars related to banks and issued by the Central Bank of Tunisia.

Wherei, $\mathrm{j}=1, \ldots, \mathrm{k}$ are the indices of all these credit states with $\mathrm{i}=1$ denotes the best credit quality andi $=4$ denotes default.

Let this credit state process defined asa Markov chain processover fixed time points $\mathrm{S}_{t=1}, \mathrm{~S}_{t=2}, \ldots, \mathrm{S}_{t=m}$. LetP(s,t) denote the $\mathrm{k} \times \mathrm{k}$ transition probability matrix that presents this credit state process at any time interval; Then, for two states $\mathrm{i}$ and $\mathrm{j}, \mathrm{P}(\mathrm{s}, \mathrm{t})=p_{i j}(s, t)=P\left(s_{j}(t) \backslash s_{i}(t-1)\right)$, that is the probability of being in credit state $\mathrm{j}$ at time $t$, conditional on being in credit state $\mathrm{i}$ at time $\mathrm{t}-1$.

So, the migration probability matrix to be estimated is as following:

$\mathrm{P}=\left[p_{i j}\right]\left[\begin{array}{llll}\mathrm{p}_{11} & \mathrm{p}_{12} & \mathrm{p}_{13} & \mathrm{p}_{14} \\ \mathrm{p}_{21} & \mathrm{p}_{22} & \mathrm{p}_{23} & \mathrm{p}_{24} \\ \mathrm{p}_{31} & \mathrm{p}_{32} & \mathrm{p}_{33} & \mathrm{p}_{34} \\ \mathrm{p}_{41} & \mathrm{p}_{42} & \mathrm{p}_{43} & \mathrm{p}_{44}\end{array}\right]$

Where $\mathrm{pij} \geq 0$ for alli, $\mathrm{j}, \sum_{j=1}^{k} p_{i j}=1$ for alli andk=4

The default is assumed to be anan absorbing state which means that assets classified 4 are lost.Then, the final row of the transition matrix $\left(\begin{array}{llll}\mathrm{p}_{41} & \mathrm{p}_{42} & \mathrm{p}_{43} & \mathrm{p}_{44}\end{array}\right)$ consists of zero for the first three entries and of one for the entry on the diagonal.

The most used method to estimate migration matrices is the cohort method (Perilioglu and Tuysuz, 2015; Schechtman, 2013); If $n_{i j}$ is the number of borrowers started in classification $\mathrm{i}$ at $\mathrm{t}-1$ and ended up in classification $\mathrm{j}$ at $\mathrm{t}$. The estimated transition probability of migrating from $\mathrm{i}$ to $\mathrm{j}$ isthe migrationfrequency of the proportion $n_{i j}$ compared to the proportion ofagents $N_{i}$ that was $\mathrm{i}$ in $\mathrm{t}-1$. Then the estimation is as follows:

$$
\widehat{p_{i j}}=\frac{n_{i j}}{N_{i}}
$$

In order toovercome the shortage of data on individual transition matrice of different economic agents in Tunisia and in view of hiding the true financial situation by borrowers, we employ a transition matrices estimation from proportions data as proposed by Jones (2005).

Such methodology requiring aggregate data is attractive for a country like Tunisia which is pursuing a policy of strengthening banking sector supervision but don't provide complete database on credit risk classification of debtors.

Jones (2005) suppose that instead of observing credit quality states sequence for each unit of observation, we observe the aggregate data for the proportion in each state ; let consider $y_{j}(t)$ and $y_{i}(t-1)$ the proportions of observations with credit quality $j$ and $i$ respectively. We can write a stochastic recursion of the form:

The matrix form of this equation is as following:

$$
y_{j}(t)=\sum_{i} y_{i}(t-1) p_{i j}+\mu_{j}(t)
$$

$$
\mathrm{y}=X p+\mu
$$

where

$$
\begin{aligned}
y & =\left(\begin{array}{lllll}
y_{1} & y_{2} & \cdots & y_{R-1}
\end{array}\right)^{\prime} \\
y & =\left(\begin{array}{llll}
y_{1}(1), y_{1}(2), \ldots, y_{1}(T) & y_{2}(1), y_{2}(2), \ldots, y_{2}(T) & \cdots & y_{R-1}(1), y_{R-1}(2), \ldots, y_{R-1}(T)
\end{array}\right)^{\prime} \\
X_{j} & =\left[\begin{array}{cccc}
y_{1}(0) & y_{2}(0) & \cdots & y_{R}(0) \\
y_{1}(1) & y_{2}(1) & \cdots & y_{R}(1) \\
\vdots & \vdots & \ddots & \vdots \\
y_{1}(T-1) & y_{2}(T-1) & \cdots & y_{R}(T-1)
\end{array}\right] \quad \text { for } \mathrm{j}=1,2, \ldots, \mathrm{R}-1
\end{aligned}
$$


So

And

$$
X=\left[\begin{array}{cccc}
X_{1} & 0 & \cdots & 0 \\
0 & X_{2} & \cdots & 0 \\
\vdots & \vdots & \ddots & \vdots \\
0 & 0 & \cdots & X_{R-1}
\end{array}\right]
$$

$p=\left(\begin{array}{llll}p_{1} & p_{2} & \cdots & p_{R-1}\end{array}\right)^{\prime}$

$p=\left(p_{11}, p_{21}, \ldots, p_{R 1} \quad p_{12}, p_{22}, \ldots, p_{R 2} \quad \cdots \quad p_{1, R-1}, p_{2, R-1}, \ldots, p_{R, R-1}\right)^{\prime}$

$\mu=\left(\begin{array}{llll}\mu_{1} & \mu_{2} & \cdots & \mu_{R-1}\end{array}\right)^{\prime}$

$\mu=\left(\mu_{1}(1), \mu_{1}(2), \ldots, \mu_{1}(T) \quad \mu_{2}(1), \mu_{2}(2), \ldots, \mu_{2}(T) \quad \cdots \quad \mu_{R-1}(1), \mu_{R-1}(2), \ldots, \mu_{R-1}(T)\right)^{\prime}$

Then, we review the constrained least-squares estimator of the transition probability matrix $\mathrm{P}$ from proportions data, minimized by quadratic forms of the type:

Subject to $\sum_{j=1}^{R-1} p_{i j} \leq 1$

$$
\text { Minimize }_{p} u^{\prime} u=(y-X p)^{\prime}(y-X p)
$$

and $\sum_{j=1}^{R-1} p_{R j}=0$

with $p_{i j} \geq 0$

\section{Data}

The database used in this study is based on data drawn from publishdregistration documents and annual financial reports, available on the website of the Financial Market Council in Tunisia,the data cover the main commercial banks and 7 leasing companies in Tunsia.It consists of time series of credit risk classifications of loans at eightmainTunisian banks (BH, STB, BNA, BIAT, BT, Attijari bank, ATB and UIB)and at 7 leasing companies (ATL, AIL, El Wifack, Hannibal Lease, Attijari leasing, CIL and TL), the period of 12 years from 2003 until 2014 has been taken into consideration.

We test the model under different circumstances: by following both public and private banks and also another banking sector activity which is Lease.

The data exclude banks that didn't publish the breakdown of their loans per credit risk class such as Amen Bank and UBCIand newly created commercial banks because they don't have sufficiently longtime seriesof observations to use Markov Transition Matrices with Proportions Data.

The Risk classes are defined by Tunisian central bank circular $N^{\circ} 91-24$ of Decemer $17^{\text {th }}$, 1991as follows:

Class 0: current assets, are considered as current assets, assets whose realization or full recovery in time seems assured.

Class 1: assets requiring special monitoring, all assets the realization or full recovery in time is still guaranteed are included in Class 1. These assets are held on companies that sector is in difficulty or that the financial situation is fragile

Class 2: uncertain assets, including all assets the realization or full recovery in time is doubtful and loans for which payment delays are greater than 90 days and lower than 180 days.It also includes assets unresolved within 90 days without exceeding 180 days.

Class 3: assets source of Concern, it considers all assets whose realization or recovery is threatened and loans $t$, for which payment delays are greater than 180 days and lower than 360 days. It also includes other assets unresolved within 180 days without exceeding 360 days.

Class 4: impaired assets, it includes in this class loans for which payment delays are greater than 360 days, the assets remained outstanding for a period exceeding 360 days and other assets that must be charged-off.

The class 4 is assumed to be the default or the absorbing state or the non reversible state (it means if a firm reach this state can never return to another credit rating (Jafry and Schuermann, 2004))

Loans amounnts per credit risk class are converted into proportions in order to be utilized by the model, in such a 
way that for each year of the study period, four categories of loans or leases quality are expressed as percentage of total loans or leases.

The credit quality grades we follow in the study consist in four risk grades:

- Risk grade 1: proportion of performing loans (total of class 0 and class 1 ) in the total bank claims,

- Risk grade 2: proportion of non performing loans of the class 2 in the total bank claims,

- Risk grade 3: proportion of non performing loans of the class 3 in the total bank claims,

- Risk grade 4: proportion of non performing loans of the class 4 (assimilated to default state) in the total bank claims.

- Descriptive Analysis

The descriptive statistics for the credit risk classification of the sample of public and private banks and leasing companies considered in this paper are reported on table 1 to table 3.

Table 1. Categories of credit quality in public banks

\begin{tabular}{lcccr}
\hline & Risk grade 1 & Risk grade 2 & Risk grade 3 & Risk grade 4 \\
\hline Mean & 0,77504845 & 0,02154105 & 0,01773665 & 0,18567385 \\
\hline Median & 0,79710968 & 0,01623766 & 0,01372204 & 0,16949049 \\
\hline Std. Dev. & 0,09077902 & 0,01729916 & 0,01180698 & 0,07510388 \\
\hline Minimum & 0,58889169 & 0,01155029 & 0,00795359 & 0,09471567 \\
\hline Maximum & 0,87865124 & 0,07202604 & 0,05150766 & 0,37204346 \\
\hline Sum & 9,30058136 & 0,25849265 & 0,21283983 & 2,22808616 \\
\hline observations & 12 & 12 & 12 & 12 \\
\hline
\end{tabular}

Table 2. Categories of credit quality in private banks

\begin{tabular}{lrrrr}
\hline & Risk grade 1 & Risk grade 2 & Risk grade 3 & \multicolumn{1}{c}{ Risk grade 4 } \\
\hline Mean & 0,86410871 & 0,00927953 & 0,00866097 & 0,11795079 \\
\hline Median & 0,86783771 & 0,0087307 & 0,00784206 & 0,11621278 \\
\hline Std. Dev. & 0,04458592 & 0,00442595 & 0,00391218 & 0,03862144 \\
\hline Minimum & 0,79258628 & 0,00261143 & 0,00322325 & 0,06616856 \\
\hline Maximum & 0,91796964 & 0,01708296 & 0,01548926 & 0,17859364 \\
\hline Sum & 10,3693046 & 0,11135434 & 0,10393162 & 1,41540949 \\
\hline observations & 12 & 12 & 12 & 12 \\
\hline
\end{tabular}

Table 3. Categories of credit quality in leasing companies

\begin{tabular}{lrrrr}
\hline & Risk grade 1 & Risk grade 2 & Risk grade 3 & Risk grade 4 \\
\hline Mean & 0,86995252 & 0,01256229 & 0,01038094 & 0,10710425 \\
\hline Median & 0,89918248 & 0,0111145 & 0,00769068 & 0,08514725 \\
\hline Std. Dev. & 0,05570782 & 0,00591622 & 0,00639617 & 0,04674944 \\
\hline Minimum & 0,78414331 & 0,00561773 & 0,00328578 & 0,0539073 \\
\hline Maximum & 0,92249812 & 0,02570038 & 0,02025412 & 0,18648104 \\
\hline Sum & 10,4394303 & 0,15074743 & 0,12457133 & 1,28525096 \\
\hline observations & 12 & 12 & 12 & 12 \\
\hline
\end{tabular}

The descriptive statistic of the category 1 of credit quality shows that the mean of performing loans proportion 
held by the private baks and leasing are at the same level of $86 \%$, while it's less important in public banks.For the second category and the third category, their average is very low in the three samples, but remain higher at public banks. The fourth and the riskiest category, the proportion mean reach $18 \%$ in public banks versus $11 \%$ and $10 \%$ in private and leasing companies respectively.

Moreover, the descriptive statistic of the credit risk categories demonstrates that standard deviation is very low in all cases and the highest ones are registered in public banks.

These results show that public banks are riskier than private and leasing companies in spite of the state support.

The selected time series are plotted in figures 1 to 3.propotion data of four credit quality grades for the period 2003-2014. If we follow the evolution within time of these four categories for the three chosen groups, we remark that:

- For the public banks,a graphic including the evolutionary curves of the four categories of credit quality can be analyzed in a time slicing (figure 1). It seems possible to identify three main phases for category 4 of credit risk: between 2003 and 2004, propotion of non perfoeming loans in class4 was considerably increased. Between 2004 and 2011, there was a decrease of this proportion in the main public banks. And finally between 2011 and 2014, the trend was changing another time to a slight increase. While the performing loans proportions (category 1) follow the opposite way of the default (category 4) but there is in a final way an increase of category 1 in 2014 compared to2003,

- For the private banks, figure 2 shows a relatively stable evolution of different credit risk categories within the period 2003-2014.

- For the leasing activity, we can note from figure 3 that there was aa slight increase of category 4 of credit quality between 2004 and 2005, then, it was decreasing until 2014. While, the plot of category 1 was having the opposite trend compared to that of category 4

It should be noted that the proportion of category 2 and 3 were very low and approximately equal in all cases studied, also their respective evolution was stable all over the period of study.

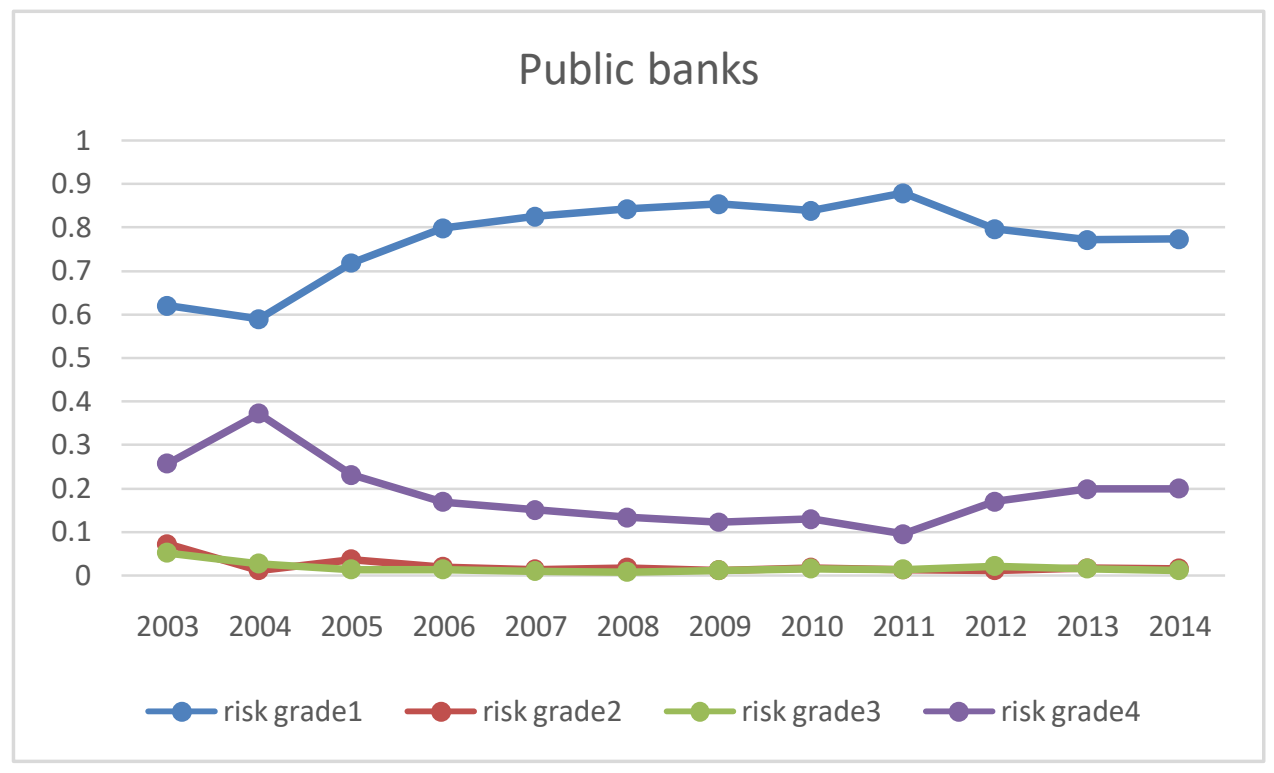

Figure 1. Classification of assets for the public banks (2003-2014)

\section{Results}

To evaluate the credit risk and their changes,we apply the proposed methodology to the time series of three public banks, 5 private banks and 7 leasing companies from 2003 to 2014.

The first step in applying the methodology is to standardize the time series into proportions data.

Second, we use quadratic programming to estimate the transition matrice. Scilabsoftware (version 5.5.2) was used to perform the analysis for the current study. It offers two commands to solve such system (qpsolve and qld). Only using command qpsolve in conceiving the algorithm of our methodology onscillaballow us to find 
solutions.

Then, transition matrices are estimated for the credit quality in public banks, private banks and leasing companies.Finally, the obtained matrices are compared

We expect that transition probabilities are more important in the sense of downgrading than upwarding and that the migration probability changes with the change of the credit institution activity. Credit and leases in private banks and leasing companies are not expected to have high risk to default, contrarily to public banks.

\subsection{Transition Matrices}

Table 4 presents the results of the estimated Markov transition matrix using proportions data for the public banks. It illustrates the general pattern of transition matrice in this study. Results indicate that:

- A high graded credit has greater tendency to bedowngraded than to be upgraded. It can be viewed on the transition matrix that the proportion of credits classified in category 2 have $95 \%$ chance to migrate to a lower category and have only $3 \%$ chance to migrate to a higher grade.

- The highest graded credit can only be downgraded with a probability of $0,4 \%$ or remain unchanged at the same category 1

- For the category 3 , downgrade is 0 and upgrades are $94 \%$.

- The transition matrix shows less probability on the diagonal and more probability on the extreme columns of category 1 and category 2 . We can deduce that there is a strong mobility of the transition matrix, especially when the credit is classified in category 2 or 3.

- It's also interesting to note that in right low corner of table 4, probabilities for transitions between classifications are low.

- we provide evidence on the asymmetry of the migration matrix, in fact probabilities of degradation of credit category is higher than probabilities of upgrading.

- the migration probabilities are not dominant on the diagonal, this pattern can be explained by the fact that there is a low probability to remain in the same category for class 2 and 3.

- Credit classified at category 2 have an important probability to finish with default (50,38\%), while category 1 and category 3 have a zero probability to migrate to default state

\begin{tabular}{lcccc}
\hline & Risk Grade1 & Risk Grade2 & Risk Grade3 & Risk Grade4 \\
\hline Risk Grade1 & 0,9963 & 0,0037 & 0 & 0 \\
\hline Risk Grade2 & 0,0304 & 0,0172 & 0,4486 & 0,5038 \\
\hline Risk Grade3 & 0,4668 & 0,4788 & 0,0544 & 0 \\
\hline Risk Grade4 & 0 & 0 & 0 & 1 \\
\hline
\end{tabular}

The estimates of the transition matrix using proportions data for the private banks are shown in table 5. Results reveal that:

- Once a borrower is in the category 3 , there is a high probability $(68 \%)$ that it will migrate to category 2 , while there is only $32 \%$ of chance that it will stay in its same grading.

- The probability to stay in category 1 is $99,7 \%$, while the creditrisk grading in the other states move around more. For credit classified in category 2, there is a zero probability that it remains in the same category, while it's more likelely to be upgraded to category 1 with $77 \%$ and to be downgrading with $23 \%$ of chance.

- Transition of credit risk grade to the default state is zero for all the categories 1, 2 and 3

-The estimated transition matriceusing proportion data exhibit asymmetrical migration shape: the probabilities of the upgrades are higher than probabilities of downgrades.

- In general, credit quality transition matrices show high migration probabilities on the diagonal and then it's the probability next to the diagonal (Banjia 2002). However, this pattern is not noted in our estimated transition matrix for the private banks credit quality. It follows that credit in private banks are most likely migrated to 
another grade and more the time to a higher grade. This can be explained by a phenomenon of not classifying someloans in the adequategrade due to a wrong assessment of the companies holding the doubtful receivables.

\begin{tabular}{lcccc}
\hline & Risk Grade1 & Risk Grade2 & Risk Grade3 & Risk Grade4 \\
\hline Risk Grade1 & 0,9976 & 0,001 & 0,0013 & 0,0001 \\
\hline Risk Grade2 & 0,7737 & 0 & 0,2263 & 0 \\
\hline Risk Grade3 & 0 & 0,6818 & 0,3182 & 0 \\
\hline Risk Grade4 & 0 & 0 & 0 & 1 \\
\hline
\end{tabular}

Table 6 displays the estimates of the transition matrix for the sample of leasing companies, the results unveil:

- No credit risk grade migratesto default state in the period of study.

- Lease credits classified in category 1 get $99,7 \%$ to keep their score or can migrate into category 2 with a transition probability equal to $0,3 \%$.

- the category 2 of credit risk can fall to category 2 in $50 \%$ of cases or stay at the same grade in the other $50 \%$ of cases.

- All lease credit of category 3 see their classification upgraded to category 1.

- Thus, the table 6 indicate that the transition matrix exhibits an asymmetric pattern and the upgradation in the grading is higher than the downgradation

\begin{tabular}{lcccc}
\hline & Risk Grade1 & Risk Grade2 & Risk Grade3 & Risk Grade4 \\
\hline Risk Grade1 & 0,9973 & 0,0027 & 0 & 0 \\
\hline Risk Grade2 & 0 & 0,4979 & 0,5021 & 0 \\
\hline Risk Grade3 & 1 & 0 & 0 & 0 \\
\hline Risk Grade4 & 0 & 0 & 0 & 1 \\
\hline
\end{tabular}

\subsection{Comparison of Migration Matrices}

In order to compare between Tunisian credit institutions at the level of credit risk in which they operate, we compare in the rest of this paper estimated transition matrices of three groups of: public banks, private banks and leasing companies.

Among the three groups analysed, the estimated migration matrix for public banks displayhigher transition probability fromrisk-grade 2 to the default state than private banks and leasing companies.

A reason for this may be that these banks have been operating in range of credit risk related to economic sectors in difficulty and mainly funded by public banks (agriculture primarily financed by BNA; Tourism sector funded in part by STB; Estate sector principally financed by $\mathrm{BH}$ )

Leasing companies migration matrix presents the highest transition probabilities from risk-grade 2 To risk-grade 3 , whereas private banks display the lowest one.

In the other hand, the three groups of financial institutions experience close transitionbehaviour of credit risk when starting from risk-grade 1 (performing loans)and migrating to grades of NPL. While, they present different risk profile when it's about non performing loans starting from grade 2 or 3 and migrating to other classes.

Besides, leasing companies display a more serious degradation of risk-grade 2 to risk grade 3 than the public and the private banks. 
Furthermore, private banks present the highest improvement of credit quality from category 2 to category 1 . While, public banks and leasing companies have this migration rate assimilated to zero of chance to improve.

The three credit institutionsseem similar considering improvement of credit quality of category 3 to risk-grade 1 or 2; The highest improvement to class 1 appears in leasing companies and the highestimprovement to class 2 is registred in private banks.

In deduction, transition trajectories depict differences with regard to the paths of migration $(2 \rightarrow 4 ; 2 \rightarrow 3 ; 2 \rightarrow$ $1 ; 3 \rightarrow 2 ; 3 \rightarrow 1$ ) between credit institutions. Exploring these trajectories, we note asymmetric pattern of the estimated transition matriceswith a majority of upgrading on downgrading for private banks and leasing companies, except the case of public banks where downgrading migrations exceed upgrading ones, we observe also that there is a low probability of staying at the same risk-grade, except category 1 wich very high. we affirm then that public banks are the riskiest creditintitution while the leasing companies are the least risky.

We identify public banks, among the three types of credit institutions analyzed, as the most risky credit institutions. They have a greater migration towards the deterioration of the classification of their bad debts compared to private banks and leasing companies, probably related to the nature of the sectors financed by the public banks.

We note also in comparingpublic and private banks that the estimated transition matrices for both have an asymmetric and non-monotonic profile, and have little concentration on the diagonals, which show a lack of rigorin the loan classificationof these banks.

\section{Conclusion}

In order to alleviate the lack of data on changes of credit quality in Tunisian financial institutions, we propose touseproportions data toestimate Markov transition matrices of credit riskin the sense of Jones (2005).The proposedcredit risk evaluation method allows to resemble more reality by considering the development of credit quality in public banks, private banks and leasing companies.

Transition matrices estimations are made upon the sequence of temporal data of credit risk classification from 3 forms ofcreditinstitutons in Tunisia (public banks, private banks and leasing companies) along twelve years of operations.

These transition matrices present a high mobility, the majority of time, on the improvement direction. They are helpful to explore diverse credit quality migrations, showing characteristics about asymmetry, monotonicity.

This paper indicates thatpublic banks have more severe downgarde migration of their non performing loans comparatively to private banks and leasing companies, which is probably related to the kind of sectors funded by the public banks. It appears also that dissimilarities between the the credit institutions studied are more pronounced at downgrading transition paths and that estimated transition matrices pattern are asymmetric and don't show monotonicity in the transition probabilities.

Then, Among the three forms of credit institution analyzed, we identify that the public banks are the riskiest financial institutions in the area of credit activity and that the dissimilarities exceed the similarities between the groups studied in view of worsening and improvement paths of credit quality transition.

The asymmetry and non-monotonic profile ofthe estimated transition matrices for public and private banks and also the little concentration on their diagonals shows a lack of rigor in the loan classification. It results in a grading of credit risk that does not coincide in all cases to the real quality of credit, then, the assessment of bank credit risk degree can be distorted.

Comparison between credit institutions can be useful to supervisory purposes, in fact, the worse transition path could constitute an early warning indicator to a forthcoming default or a reverse of migration path to the risky direction. Moreover, this sudy has a practical potentiality, because it can constitute a guidance tool to credit risk 
managementfor progressing toward better credit policies (growth strategy, renegociation).

\section{References}

Tunisian Central Bank (2014). Rapport sur la Supervision Bancaire. Banque Centrale de Tunisie.

IMF (2012). Tunisie: Évaluation de la stabilité du système financier. FMI report, 12/241.

J.P. Morgan \& Co (1997). CreditMetrics ${ }^{\mathrm{TM}}$ - Technical Document. J.P. Morgan \& Co. Incorporated.

Basel committee on Banking Supervision (2003). The New Basel Capital Accord: consultative document. Bank for International Settlements.

Basel committee on Banking Supervision (2004). International convergence of capital measurement and capital standards. Bank for International Settlements.

Basel committee on Banking Supervision (2010). Basel III: A global regulatory framework for more resilient banks and banking systems. Bank for International Settlements.

Bajaj, R.V.(2010). Migration analysis of Indian corporate: Rating-Based approach. The IUP Journal of Financial Risk Management, 7, 24-34.

BCT (2014). Rapport sur la Supervision Bancaire. Tunisian Central Bank.

Ivičić, L.,\&Cerovac, S.(2009). Credit risk assessment of corporate sector in Croatia.Financial Theory and Practice, 33, 373-399. http://hrcak.srce.hr/48606

Jafry, Y., \&Schuermann, T. (2004). Measurement, estimation and comparison of credit migration matrices. Journal of Banking \& Finance, 28, 2603-2639.doi:10.1016/j.jbankfin.2004.06.004

Grzybowska, U., Karwańskia, M. \&Orłowski, A. (2012). Examples of migration matrices models and their performance in Credit Risk Analysis.doi:10.12693/APhysPolA.121.B-40

Jones, M. (2005). Estimating Markov transition matrices using proportions data : an application to credit risk. IMF working paper 05/219

Nicula, I. (2013). Some aspects concerning the measurement of credit risk.Procedia Economics and Finance, 6, 668 - 674. doi: 10.1016/S2212-5671(13)00187-1

Lando,D.\&Skødeberg, T. (2002) .Analyzing rating transitions and rating drift with continuous observations. Journal of Banking \& Finance, 26, 423-444. doi: 10.1016/S0378-4266(01)00228-X

Perilioglu, A.\&Tuysuz, S.(2015). Conditional Sovereign Transition Probability Matrices. Procedia Economics and Finance, 30, 643-655. https://doi.org/10.1016/S2212-5671(15)01283-6

Schechtman, R. (2013).Default matrices: A complete measurement of bank's consumer credit delinquency.Journal of Financial Stability, 9, 460-474. doi:10.1016/j.jfs.2013.07.001

\section{Copyrights}

Copyright for this article is retained by the author(s), with first publication rights granted to the journal.

This is an open-access article distributed under the terms and conditions of the Creative Commons Attribution license (http://creativecommons.org/licenses/by/4.0/). 